\title{
Formas de ver y exhibir el patrimonio arqueológico indígena en dos museos de Bogotá (1938-1953)*
}

\author{
Daniel García Roldan ${ }^{*}$
}

\begin{abstract}
Recibido: 22 de enero de 2016
Evaluado: 25 de marzo de 2016

Aceptado: 1 de abril de 2016
\end{abstract}

\section{RESUMEN}

Este artículo presenta un análisis histórico sobre la creación y los primeros quince años de historia de dos museos en Bogotá: el Museo Arqueológico Nacional, fundado en 1938 y el Museo del Oro del Banco de la República, cuya colección se inició en 1939. A partir de la indagación en los contextos de formación de ambos museos, así como de las formas de valoración y exhibición de lo que en ese momento se concibió como patrimonio arqueológico indígena, no solamente se pretenden comprender las circunstancias de ese pasado reciente del que aún hoy somos herederos directos, sino también ganar un lugar de observación que nos permita considerar críticamente las maneras como actualmente se presentan esos vestigios materiales ante nuestra mirada.

Palabras clave: patrimonio arqueológico, Bogotá, Museo Arqueológico Nacional, Museo del Oro.

Artículo de reflexión. Fruto del proyecto de investigación Políticas y prácticas de la vida cultural en el centro de Bogotá, desarrollado en el Departamento de Humanidades de la Universidad Jorge Tadeo Lozano, en colaboración con investigadores de la Universidad Central. Cómo citar este artículo: García Roldán, D. (2016). Formas de ver y exhibir el patrimonio arqueológico indígena en dos museos de Bogotá (1938-1953). Hallazgos, 13(26), 149-178 (doi: http://dx.doi.org/10.15332/s1794-3841.2016.0026.06).

** Maestro en Historia y Teoría del Arte, la Arquitectura y la Ciudad, de la Universidad Nacional de Colombia. Profesor asociado, de la Universidad Jorge Tadeo Lozano. Correo electrónico: daniel.garcia@utadeo.edu.co, https://utadeo.academia.edu/danielgarciaroldan. Diagonal 61b No. 21-14 Apto 301 


\section{Ways of seeing and exhibiting the amerindian archeological patrimony in two museums of Bogotá (1938-1953)}

\begin{abstract}
The following article presents an historical analysis about the creation and the first fifteen years of history of two archeological museums in Bogotá: The Archaeological National Museum, founded in 1938, and the Gold Museum, whose collection started in 1939. Based on the inquiry of how these two museums were built, and their ways of seeing, valuating and exhibiting what it was considered archeological patrimony in that time, we pretend to understand that recent past we inherit directly, and also gain a point of view that allow us to consider the ways those vestiges are exhibit today, within a critical perspective.
\end{abstract}

Keywords: Archaeological patrimony, Bogotá, Archaeological National Museum, Gold Museum
Received: January 22, 2016

Evaluated: March 25, 2016

Accepted: April 1, 2016 


\section{Formas de olhas e exibir o patrimônio arqueológico indígena em dois museus de Bogotá (1938-1953)}

Recebido: 22 de janeiro de 2015
Avaliado: 25 de março de 2015
Aceito: 1 de abril de 2016

\section{RESUMO}

Este artigo apresenta uma análise histórica sobre a criação e os primeiros quinze anos de história de dois museus em Bogotá: o Museu Arqueológico Nacional, fundado em 1938 e o Museu do Ouro do Banco da República, cuja coleção se iniciou em 1939. A partir da indagação nos contextos de formação de ambos museus, assim como as formas de valoração e exibição do que naquele momento foi concebido como patrimônio arqueológico indígena, não somente pretende-se compreender as circunstancias de esse passado recente do qual ainda hoje somos herdeiros diretos, senão também ganhar um lugar de observação que nos permita considerar criticamente as maneiras como atualmente se apresentam estes vestígios matérias ante nosso olhar.

Palavras-chave: patrimônio arqueológico, Bogotá, Museu Arqueológico Nacional, Museu do Ouro. 


\section{UN CONTRAPUNTO A MANERA DE INTRODUCCIÓN: MÉXICO D.F. Y LAS SUPERVIVENCIAS DEL PATRIMONIO ARQUEOLÓGICO INDÍGENA}

Tal como lo narra Octavio Paz, la historia moderna de la escultura de la diosa Coatlicue, la de falda de serpientes, sirve para comprender e imaginar en qué consiste el carácter superviviente del pasado prehispánico en América. Redescubierta por azar en 1790 debajo del piso de la Plaza Mayor de Ciudad de México, la enorme piedra esculpida fue llevada a la Universidad Real y Pontificia Universidad, aunque por poco tiempo, ya que los "doctores" decidieron volverla a enterrar al considerarla una ofensa a "la idea de belleza" y una amenaza, pues su presencia podía animar antiguas creencias. En 1804 Humboldt, de paso por la ciudad, solicitó verla, pero luego la estatua volvió al subsuelo; solo después de la Independencia fue desenterrada definitivamente, aunque durante un tiempo permaneció olvidada y parcialmente oculta. Sin precisar una fecha, Paz nos cuenta que más tarde se hizo visible "como una pieza de interés científico e histórico" y solo desde hace algunas décadas ocupa un lugar central en el Museo Nacional de Antropología de México, convertida en una "obra maestra". Así, en un proceso hecho de apariciones y ocultamientos, de "muertes" y "renacimientos", no solo la escultura de Coatlicue, sino también muchos otros objetos de las sociedades indígenas que habitaron y habitan territorios americanos han abandonado paulatinamente "el territorio magnético de lo sobrenatural" para entrar de manera intermitente "en los corredores de la especulación estética y antropológica", acompañados de significados y usos cambiantes y en ocasiones contradictorios (Paz, 2006, p. 75-76).

Uno de los aspectos centrales de las supervivencias del pasado prehispánico en los procesos de construcción de las naciones modernas, y que para el caso colombiano no ha sido analizado con suficiente profundidad, es el que tiene que ver con las funciones que el denominado patrimonio arqueológico indígena cumple en las capitales de los países hispanoamericanos. No es gratuito, por ejemplo, que en el libro La ciudad de México, una historia, Serge Gruzinski decida abordar la historia de Tenochtitlán, no al comienzo sino en la mitad de su libro; es decir, como si "la ciudad" y el pasado mexica tuviesen un lugar central en el tiempo histórico de la ciudad moderna; como si no les bastara con el espacio incierto de los comienzos, y prefirieran ocupar el lugar imaginario, aunque siempre actual, de los orígenes. Al revisar las relaciones entre la historia de la arqueología y la historia de Ciudad de México, Eduardo Matos Moctezuma presenta un cuadro similar (Matos, 1998). La capital de Nueva España, y posteriormente el Distrito Federal, están marcados por el redescubrimiento, la exhibición pomposa o marginal y el estudio riguroso de enormes estatuas que se encontraron bajo el suelo del centro de la ciudad o en sus alrededores, a causa de diversas obras públicas. Pocos meses después de que Coatlicue fuera descubierta, hallaron la Piedra del Sol, conocida popularmente como el calendario azteca. Esta enorme escultura estuvo adosada a uno de los muros laterales de la catedral durante casi un siglo, hasta que en 1895 conquistó un lugar en la sala de monolitos del Museo Nacional. Algo similar ocurrió con la Piedra de Tizoc encontrada en 1791. Con ellas 
nacieron, según Matos (1998), los primeros tratados de arqueología en México (p. 28).

Sin embargo, y de acuerdo con varios puntos de la perspectiva de Federico Navarrete, lo que ha nacido y se ha consolidado es una arqueología "monolítica", asociada de manera demasiado estrecha a las instituciones y al poder estatal, y con ello a su perspectiva instrumental del patrimonio indígena como símbolo de la nación (Navarrete, citado en Gnecco et al., 2010, 67). Ello explica, por ejemplo, los grandes esfuerzos que convergieron en la recreación del Museo Nacional de Antropología en su sede de los bosques de Chapultepec en 1964, que con su montaje apuntó (tal como lo interpretó Néstor García Canclini) a contraponer la monumentalidad y la miniaturización, y los objetos indígenas del pasado con los del presente, con lo cual se creó un mosaico que simboliza, con una pretensión de totalidad, al pueblo mexicano (García, 2001, p. 169). Asimismo, esa arqueología "monolítica" impulsó los posteriores trabajos de excavación en el centro de la ciudad a partir del hallazgo en el subsuelo del Zócalo en 1978, de la enorme escultura de Coyolxauqui, hija de Coatlicue. Este descubrimiento hizo que José López Portilla, el presidente de México en ese momento, expropiara varias manzanas para encontrar las ruinas del Templo Mayor (Navarrete, citado en Gnecco, 2010, p. 66). Hoy en día, el museo que surgió de este proyecto arqueológico de largo aliento presenta un guion que pretende develar la estructura de poder y dominación en la que estaba inserto el pueblo mexica. Sin embargo, su propósito no alcanza a sobreponerse a la emoción heroica que las esculturas, exhibidas con dramatismo, imprimen en los visitantes, ni a acallar las voces de los guías informales que narran una historia gloriosa de los "antepasados" a pocos metros del museo, donde se encuentra la fuente decorada con la maqueta de la gran Tenochtitlán (Rosas, citado en Sunkel 2006, p. 260).

Estas tensiones con respecto al significado y al uso del pasado indígena, que tuvieron y aún tienen lugar en los museos e instituciones de varias ciudades hispanoamericanas a partir del siglo $\mathrm{xx}$, son las que se pretenden estudiar en este artículo, haciendo enfoque en el caso de Bogotá. En esta ciudad, la reaparición del pasado prehispánico de la que aún somos partícipes tuvo lugar a partir de 1938, luego de la exposición arqueológica etnográfica que organizó Gregorio Hernández de Alba con motivo de la celebración del IV centenario de la fundación de la ciudad. No sobra agregar que este acontecimiento estuvo envuelto en una ola general de transformación con respecto a las formas de concebir y atesorar el patrimonio arqueológico indígena, tanto en el continente americano como en Europa. El médico y etnólogo Paul Rivet, que ejerció una gran influencia en la arqueología, la etnología y la antropología latinoamericanas durante la primera mitad del siglo $\mathrm{xx}$, fue el gestor de la creación del Museo del Hombre, que abrió sus puertas el 20 de junio de 1938 en París. El año siguiente se fundó el Instituto Nacional de Antropología e Historia (INAH) de México, institución clave para el desarrollo de la investigación y conservación de monumentos indígenas en ese país. En 1941, parte de las colecciones del Museo Arqueológico de Madrid fue la base para la inauguración del Museo de América en la capital española (Vázquez, 1954, p. 5).

¿Qué sucedió en Bogotá durante esos primeros años en los que se crearon las 
colecciones y se fundaron las instituciones y museos que, aunque con algunas modificaciones, aún hoy existen y organizan parcialmente nuestra percepción del pasado prehispánico? Se espera que las siguientes páginas ayuden a resolver estos interrogantes, a partir de la indagación en las formas de observación, valoración y exhibición de lo que en ese momento se concibió como patrimonio arqueológico, ${ }^{1}$ en dos museos que surgieron paralelamente: el Museo Arqueológico Nacional creado en 1938, con el apoyo del Servicio de Arqueología y del Instituto Etnológico Nacional, instituciones que se fundieron en una sola a partir de 1945, y el Museo del Oro, que durante los primeros años fue la colección de orfebrería del Banco de la República (iniciada en 1939), y que de forma gradual y lenta comenzó a cumplir las funciones propias de un museo, aunque ya desde 1943 se denominara así (Duque, 2004, pp.17-22). Con este breve análisis histórico, no solamente se pretenden comprender las circunstancias de ese pasado reciente del que aún hoy somos herederos directos, sino también ganar un lugar de observación que nos permita considerar críticamente las maneras como actualmente se presentan esos vestigios materiales ante nuestra mirada.

\section{UN BREVE ESTADO DEL ARTE DE LA CUESTIÓN: LA HISTORIA DE LA ANTROPOLOGÍA EN Colombia y de los MUSEOS ARQueOLÓgICOS EN Bogotá}

Algunos de los autores que durante las últimas dos décadas se aventuraron a investigar sobre estos temas con una perspectiva

1 En 1943, el ministro de educación, Rafael Parga, se refirió a los objetos prehispánicos como patrimonio histórico (1943, p. 7). histórica han hecho aportes significativos para comprender los puntos críticos a partir de los cuales se valoraron y estudiaron los vestigios arqueológicos en Colombia a mediados del siglo $\mathrm{xx}$; sin embargo, no se ha abordado a fondo el problema de las distintas prácticas museográficas que los ordenaron y las formas de valoración que ellas produjeron. En primer lugar, los trabajos de Carl Langebaek y de Roberto Pineda proporcionan un cuadro más o menos completo de los actores involucrados en este proceso, aunque sus temas de interés sean otros. En el caso de Pineda, prima la historia de los institutos etnológicos nacionales, de los conflictos y batallas de sus protagonistas y del compromiso político de estos intelectuales con el del indigenismo para resolver las crisis de comunidades indígenas frente a la pérdida de su lengua y de sus tierras (2009, 2014). En el de Langebaek, prima la historia de la arqueología en Colombia, de los conflictos entre investigadores nacionales y extranjeros, y de los debates en torno a la raza que fueron dominantes durante esas décadas, y permearon los diferentes campos de estudio de las culturas y sociedades indígenas (2003, 2009, 2010).

En un plano más específico, es necesario tener en cuenta las investigaciones que se han llevado a cabo sobre Gregorio Hernández de Alba, precursor de la arqueología, la etnología y la antropología en Colombia. En el libro Caminos de la Antropología: Gregorio Hernández de Alba (2006), Jimena Perry presenta una biografía intelectual de este estudioso de las ciencias del hombre que resulta fundamental para comprender la formación de los museos arqueológicos e institutos etnológicos en Bogotá, ya que Hernández de Alba se destacó por ser gestor y promotor 
de ambas instituciones. Además, el trabajo de Perry resulta valioso en dos sentidos. En primer lugar, porque muestra el creciente compromiso político de este intelectual con el indigenismo; en medio de cambios de trabajo y de crisis laborales, Hernández de Alba pasó de ser el director del Servicio de Arqueología en 1938, adscrito al Ministerio de Educación, para convertirse en Jefe Administrativo de la Sección de Resguardos Indígenas, adscrito al Ministerio de Agricultura, en 1958. En segundo lugar, el trabajo de Perry es relevante, pues a partir del rastreo de la vida profesional de Hernández de Alba, la autora también da cuenta de los momentos afortunados y difíciles en la historia de los estudios de arqueología, etnología y antropología en el país. Si entre 1940 y 1948 una serie de intelectuales e instituciones nacionales y extranjeras impulsaron el desarrollo de estas disciplinas, durante el periodo de la violencia dicho desarrollo se vio truncado con el cierre de institutos y la persecución política de algunos de sus investigadores (Perry, 2006, pp. 63-70).

En la misma dirección, los estudios sobre la vida intelectual de Gregorio Hernández de Alba se han nutrido recientemente con un ensayo de Roberto Pineda Camacho y dos ensayos de Carlos Andrés Barragán, que hacen parte de la introducción de La cultura arqueológica de San Agustín (2014). Este libro fue la tesis escrita por Hernández de Alba durante su estadía en París como agregado del Departamento de América en el Museo del Hombre y como asistente a los cursos del Instituto de Etnología (1938-1939); sin embargo, nunca fue sustentada ni publicada en vida del autor, y solo en 1978, cinco años después de su muerte, su hijo Gonzalo la tradujo y la publicó. Los textos de
Pineda y de Barragán para esta nueva edición abordan la historia del manuscrito, los primeros años de formación de Hernández de Alba y "el ensamblaje intelectual, científico y político que puso en movimiento para la gestación y sostenimiento de redes de producción de conocimiento etnológico entre 1934 y 1945" (Barragán, 2014, p. 99). Estos trabajos son de gran utilidad para comprender más detalladamente, tanto en el nivel local como global, el surgimiento de las investigaciones y grupos vinculados con la investigación arqueológica y etnológica en Colombia a mediados del siglo xx. Asimismo, otro aspecto valioso en los trabajos de Barragán consiste en las acertadas críticas a algunos de los estudios que se han ocupado de la historia de la arqueología y antropología en Colombia durante los últimos años. ${ }^{2}$

Pasando de un plano general de la cuestión a textos más específicos sobre la historia de los museos, es necesario mencionar los trabajos de Santiago Londoño (1989) y Efraín Sánchez (2003) sobre la historia del Museo del Oro. En ambos casos se trata de textos que reconstruyen cronológicamente las labores filantrópicas de esta institución y la nobleza de las directivas del Banco de la República en el contexto general del desarrollo de "las ciencias del hombre". Esta tarea, en cualquier caso necesaria y significativa, resulta insuficiente, pues ni en el trabajo de Londoño, ni en el de Sánchez se lleva a cabo un análisis crítico del desarrollo histórico del museo. Esto muy probablemente tiene que ver con el hecho de que en el primer caso se trata de un encargo del Banco de la República para conmemorar los 50 años del

2 Por ejemplo, de la interpretación que Karl Langebaek hace de la polémica entre Gregorio Hernández de Alba y José Perez de Barradas. 
Museo del Oro; y en el segundo, de un artículo publicado en el boletín de esta institución. A ello se agrega que la versión digital del texto de Sánchez es presentada en la página web del museo como una especie de "documento oficial" en el cual el visitante puede conocer su historia. En ese sentido, no es de extrañar que los textos no se distingan por su postura crítica. Tampoco resulta excepcional que no se pregunten por la relación que esta institución cultural ha mantenido con el banco emisor que la hizo posible, y que carezcan de una perspectiva comparativa capaz de poner en relación las prácticas de colección, valoración y exhibición del Museo del Oro con las de otras instituciones que simultáneamente estaban llevando a cabo la misma labor.

Por último, están los artículos de Marcela Echeverri (1999) y Jimena Perry (2009), y los trabajos de Clara Isabel Botero (1996, 2001, 2006, 2009, 2010). En los dos primeros casos, la premisa teórica de que la alteridad ${ }^{3}$ es irrepresentable y termina recrudeciendo estereotipos y legitimando formas de dominación, ya sea de estados nacionales o de ciertos grupos sociales, empobrece la capacidad de las autoras de realizar análisis específicos de los relevantes datos que recogen sobre las exposiciones y museos arqueológicos en Bogotá, entre 1938 y 1948. Otro es el caso del libro de Clara Isabel Botero ${ }^{4}$ titulado El redescubrimiento del pasado prehispánico de Colombia: viajeros, arqueólogos y coleccionistas 1820-1945 (2006), que aporta

3 Referida en este caso a las sociedades indígenas del pasado y el presente.

4 Además de este libro, se encuentran algunos artículos y capítulos de libros sobre museos arqueológicos y antropológicos en Colombia, así como una importante recopilación de documentos de la correspondencia entre Paul Rivet y José de Recasens (Botero, 2010). importantes pistas para comprender que el proceso de construcción de valor de los objetos arqueológicos es de larga duración (pues se remonta a los comienzos de la Colonia) y en él se entremezclan una serie de prácticas contradictorias. En primer lugar, la demonización y la exotización de las culturas indígenas como dos caras de la misma moneda, que permitieron por un lado la expropiación de objetos de culto considerados ilegítimos y, por otro lado, su atesoramiento y transformación en "maravillas". En segundo lugar, el surgimiento de un mercado de este tipo de objetos, que fue inseparable de la constitución de colecciones, archivos y reproducciones de estos; es decir, de la aparición de saberes y prácticas que si bien parecen antagónicas, estuvieron estrechamente ligadas (como sucede con la guaquería y la arqueología). En tercer lugar, la nacionalización e internacionalización de esos vestigios a través de exposiciones realizadas durante la segunda mitad del siglo XIx, que en el contexto local representaron lo indígena como lo exótico en un país católico, mientras que en el contexto internacional lo presentaron como lo propio y distintivo de la nación. Y finalmente, la consolidación de una comunidad "científica" que funcionó y aún funciona a través del debate y la polémica, y que transforma así los objetos arqueológicos en documentos "valiosos" por su capacidad de servir de soporte a las más diversas interpretaciones. Si este libro logra hacer visibles tales cuestiones, no sucede lo mismo con el texto también escrito por Botero sobre el surgimiento de los museos arqueológicos y etnográficos en Bogotá (2009), reducido prácticamente a una enumeración de los actores y acontecimientos que estuvieron ligados a este proceso, tímidamente acompañada de una reflexión final 
de Bruno Latour sobre la importancia de las colecciones en el surgimiento de la ciencia y de otra de Kristoph Pomian sobre los vestigios materiales, arqueológicos y etnográficos, como representantes visibles de lo invisible y lo desconocido.

Más allá del hecho de que los objetos arqueológicos hayan funcionado y aún funcionen como representantes de lo invisible, es necesario preguntarnos por las maneras como han sido observados, valorados $\mathrm{y}$ exhibidos, pues las condiciones de su visibilidad son diversas y ello implica nuevos problemas. Tal es la cuestión de los casos de estudio de este artículo. Empleando como fuentes principales las diversas publicaciones que acompañaron los primeros años de estas instituciones, además de algunos documentos del archivo de Gregorio Hernández de Alba que se encuentra en la Biblioteca Luis Ángel Arango y de informes y fotografías que reposan en el ICANH, se analizarán acá cuatro aspectos concretos: 1 . los contextos de formación de estos museos, es decir, con qué influencias y bajo el apoyo de qué instituciones se conformaron; 2. su historia inicial que se puede adivinar a través de un breve repaso a sus impresos; 3. las formas de concebir la museología y los objetos arqueológicos en estas dos instituciones, y 4. las representaciones de la relación entre los objetos y el espacio geográfico, que ayudaron a crear un orden y un sentido de las colecciones. Todo ello con el propósito de interrogar el tipo de mirada que cada uno de estos museos construyó sobre lo que aún hoy conocemos con el nombre de patrimonio arqueológico indígena.

\section{INFLUENCIAS Y CONTEXTOS} DE FORMACIÓN: EL ESTADO,

\section{LA BANCA Y LOS MUSEOS INTERNACIONALES}

Ya se ha mencionado en este artículo que la institución que formó el Museo del Oro fue el Banco de la República, aspecto que no resulta extraño si se tiene en cuenta que desde el Renacimiento hasta la actualidad ha existido una tradición casi ininterrumpida de familias de banqueros e instituciones bancarias que han conformado importantes colecciones privadas y corporativas de arte y objetos suntuarios. Tal como lo expone el exgerente del banco emisor, Miguel Urrutia, en el libro Banco de la República. 90 años de la Banca Central en Colombia, se pueden mencionar ejemplos sobre banqueros como Andrew W. Mellon, cuya colección fue la base de la National Gallery de Washington, o sobre J.P, Morgan quien donó una parte importante de lo que hoy constituye la colección de arte medieval del Metropolitan Museum de Nueva York, (Urrutia, citado en Alonso 2013, p. 52). En palabras del exgerente, quien dice desconocer la "razón exacta" por la cual bancos y banqueros han "promovido el arte y la cultura", el "[...] origen del interés del Banco de la República es más modesto. Sus colecciones son el resultado de decisiones administrativas de poca monta en un principio, cuyas consecuencias no se previeron" (p. 52). Para el caso del Museo del Oro, Urrutia cuenta un relato que se ha repetido en varias ocasiones según el cual a finales de los años treinta llegaron a la oficina central del Banco tres piezas de orfebrería, provenientes de una 
de las agencias regionales de compra de oro del Banco. ${ }^{5}$ A dichos objetos se sumaron otros comprados a un coleccionista particular y luego, por petición del Ministerio de Educación, la Junta Directiva decidió iniciar formalmente una colección, adquiriendo por sugerencia de Alfonso Arango, el ministro de turno en aquel momento, la emblemática pieza que actualmente se conoce con el nombre de Poporo Quimbaya.

Si bien no se trata de poner en duda la aparente modestia de las decisiones administrativas en las que muy probablemente no existía una conciencia plena de la posterior importancia del Museo del Oro, sí es necesario tener en cuenta otras fuentes para entender aspectos fundamentales que giran en torno a los inicios de la colección y que si bien no son su única causa, sin duda contribuyen a comprender este proceso desde una óptica un poco menos simple. Uno de los temas recurrentes en la revista oficial del banco entre 1940 y 1942 (año en el cual aparecieron por primera vez reproducciones fotográficas de algunas piezas de su colección de orfebrería indígena) es el de la crisis del valor del oro en la economía mundial, y particularmente en la economía norteamericana. Artículos como "El actual problema del oro" de E. A. Goldenweiser (20 de marzo de 1940), "Excesivas existencias de oro en los Estados Unidos" del Servicio de Información Panamericana (20 de julio de 1940), "El patrón de oro" (20 de marzo de 1941), "El valor monetario del oro" de John G. Phillmore (20 de marzo de 1942), o "El problema del oro en los Estados Unidos" de la Revista Bancaria y Aseguradora de Buenos

5 Desde 1923, año de la fundación del Banco de la República, y hasta 1992, esta institución controló el comercio del oro (Urrutia, citado en Alonso, 2013, p. 52).
Aires (20 de agosto de 1942) dejan ver la atención que le prestaron a este asunto las directivas del banco emisor colombiano.

A pesar del abandono del patrón oro en la economía mundial a comienzos de 1930, los analistas de finales de la década aún consideraban que el metal constituía el único "medio aceptado universalmente para equilibrar la balanza de pagos entre los países" (Goldenweiser, citado en Revista del Banco de la República, 20 de marzo de 1942, p. 91). No obstante, el comienzo de la guerra junto con otros factores provocaron una entrada descomunal de este metal a Estados Unidos que resultaba alarmante por la posibilidad de que excesivas reservas en los bancos llevaran a un crecimiento desmedido del crédito y con él a "su bien conocido séquito: la especulación, el aumento del costo de la vida $\mathrm{y}$, al final, la depresión de los valores" (Servicio de Información Panamericana, 20 de julio de 1940, p. 153, 270). Ante tal panorama, el economista Goldenweiser afirmaba: "Su desusada actuación de los últimos años ha hecho del oro un tema de discusión de mayor interés que cuando su vista era mucho más familiar de lo que es hoy, cuando se creía que su capacidad para producir el equilibrio económico era poco menos que mágica" (1942, p. 91). No se trata con ello de afirmar que las principales causas del inicio de la colección de orfebrería tengan que ver directamente con el problema del valor oro, pero sin duda es necesario reconocer que esta situación de incertidumbre que se recrudeció con el inicio del conflicto europeo obligó a considerar otras formas de valor de este metal, que aunque eran conocidas, quizás no habían sido tenidas en cuenta durante los primeros años de existencia del banco. Así, piezas orfebres que quizás habían sido 
fundidas sin miramientos para ensanchar las reservas y tener una relación de paridad con el dinero nacional comenzaron a ser vistas con otros ojos, ante la crisis causada por las transacciones internacionales de este metal. No deja de llamar la atención que en los siguientes años esta discusión perdió su fuerza en la revista del banco, y que de igual forma las fotografías de las piezas de orfebrería no volvieron a figurar en esta publicación.

Con respecto a la creación del Museo Arqueológico, un primer aspecto que vale la pena destacar es que también fue impulsada por el Ministerio de Educación y que estuvo estrechamente ligada con el desarrollo de la Escuela Normal Superior (fundada en 1937), pues algunos de sus estudiantes fueron posteriormente alumnos del Instituto Etnológico y miembros del equipo de trabajadores del museo. Asimismo, Gregorio Hernández de Alba empezó impartiendo clases en la Normal para luego ocupar el cargo de director del Servicio de Arqueología (Perry, 2006). Es necesario advertir que el surgimiento de estas instituciones estuvo enmarcado en las transformaciones que la República Liberal implantó en el campo de los proyectos de extensión cultural. Tal como lo interpreta Renán Silva, este periodo representó "una de las etapas de más alta integración entre una categoría de intelectuales públicos y un conjunto de politicas de Estado" (2005, p. 22), aspecto que además estaba ligado con un nuevo "enfoque de las relaciones entre dirigentes y pueblo, que replanteaba muchas de las formas tradicionales de dominio y hegemonía en el país": la población ya no se concebía desde la idea de las "masas pastoriles" pasivas, sino de las masas como un "sujeto activo" que, no obstante, era necesario educar y guiar (Silva, 2005, pp. 22-24). Para ello, los museos, junto con todos los medios de comunicación de masas disponibles, jugaron un papel fundamental.

Si bien este ambiente de transformación en el contexto cultural y político local resulta determinante para comprender la formación del Museo Arqueológico y el Museo del Oro, también es necesario analizar algunas de las influencias que ambos recibieron de museos en el exterior. Sin duda el caso más conocido y mencionado es el del Museo del Hombre en París. Fue allí donde Hernández de Alba consolidó su proceso de formación bajo la influencia de intelectuales como Marcel Mauss; asimismo, Paul Rivet tuvo que abandonar París ante su inminente captura por parte de los nazis y estuvo asilado en Bogotá, donde lideró la fundación del Instituto Etnológico y trabajó de manera activa durante los primeros años de la guerra, pues en 1943 partió rumbo a México. No sobra agregar que tanto el Instituto como la Escuela Normal Superior fueron instituciones que acogieron a varios europeos de distintas procedencias que habían salido del continente por la Guerra Civil Española, por la Segunda Guerra Mundial o por el aumento de viajes y circulación de personas que tuvieron lugar durante aquellos años.

Además de ser un importante referente como laboratorio de investigación, tanto Jimena Perry como Clara Isabel Botero han insistido en el carácter político del Museo del Hombre, así como en la concepción que Paul Rivet tenía de los objetos etnográficos y arqueológicos como objetos de "[...] convicción, es decir con un contenido político" (Botero, 2006, p. 247). Sin embargo, no se ha explorado con detalle en qué consistía exactamente esa militancia de la institución y 
además cómo se transformó prácticamente en un campo de batalla durante la guerra. En su reciente libro In the museum of man: race, anthropology, and empire in France, 1850-1950 (2013), Alice Conklin hace una investigación exhaustiva sobre la historia de esta institución que nos permite entender por qué para los intelectuales y políticos liberales, específicamente para Gregorio Hernández de Alba, este espacio fue un referente primordial para concebir la dimensión política y científica del proyecto del Museo Arqueológico en Bogotá. A partir de la tradición dominante de la antropología física concentrada en el estudio de las $\operatorname{razas}^{6}$ y de la experiencia francesa en las colonias, un grupo de intelectuales liderado por Rivet y Mauss reaccionó desde las primeras décadas del siglo $\mathrm{xx}$ a la intensificación del racismo, el individualismo y el autoritarismo (Conklin 2013 , p. 4), con una perspectiva crítica que se cristalizó con la creación del Instituto de Etnología (1928) y algunos años más tarde con la apertura del Museo del Hombre. ${ }^{7}$

Por un lado, la elección estratégica del término etnología alejaba al grupo liderado por Rivet de una identificación con la forma como se entendía y practicaba la antropología. Por otro lado, mediante el surgimiento del museo se hizo pública y se difundió una visión de las razas y de los pueblos denominados primitivos, que no implicaba jerarquías y escalas de valor, sino el reconocimiento y la celebración de la pluralidad y la diversidad de las culturas y sociedades humanas. Para llevar este mensaje a las masas y hacer del museo un centro de educación

6 La figura dominante con respecto a esta tradición de la antropología fue la de Paul Broca (1824-1880).

7 Este museo se formó inicialmente con la colección del Museo Etnográfico de Trocadero. popular, Rivet se apoyó en la experiencia de Georges Henri Rivière, quien estaba familiarizado con los círculos artísticos de vanguardia, conectado con periodistas e intelectuales y vinculado por asuntos laborales con importantes coleccionistas, como el banquero David David-Weill. Desde 1929 Rivière hizo una gira por los museos norteamericanos para aprender de su organización (en algunos casos, dividida en dos secciones, una para el gran público y otra para los especialistas) y a partir de 1936 visitó los museos etnográficos soviéticos. La influencia en este caso fue decisiva pues los roles científicos, educativos, artísticos y nacionales de las instituciones rusas resonaron en varios aspectos con la política francesa del Frente Popular, que estuvo al mando entre 1936 y 1938. En este punto vale la pena subrayar cómo los rusos desarrollaron una estrategia similar a la que utilizaron los museos latinoamericanos, y crearon así una identidad nacional a partir de grupos étnicos que no eran rusos. En síntesis, el aprendizaje de experiencias como la apertura hasta altas horas de la noche de las bibliotecas de los museos norteamericanos o "la noche etnográfica de la solidaridad" en la que cientos de obreros soviéticos eran invitados a hacer recorridos por los museos, asistir a cine y a espectáculos influyó en prácticas que posteriormente llevó a cabo el Museo del Hombre, como la de hacer un tour por el mundo en ocho minutos (Conklin, 2013).

Con la inminencia del conflicto y la posterior ocupación nazi, la politización del Museo del Hombre llegó a su límite, y fue en este periodo cuando Hernández de Alba estuvo presente hasta que tuvo que regresar a Colombia. En el sótano del museo se imprimió de manera clandestina el boletín 
Imagen 1. Museo del Hombre, panel sobre los Incas, fotografía, B/N, 23,9 x 18,3 cm, FG-1205

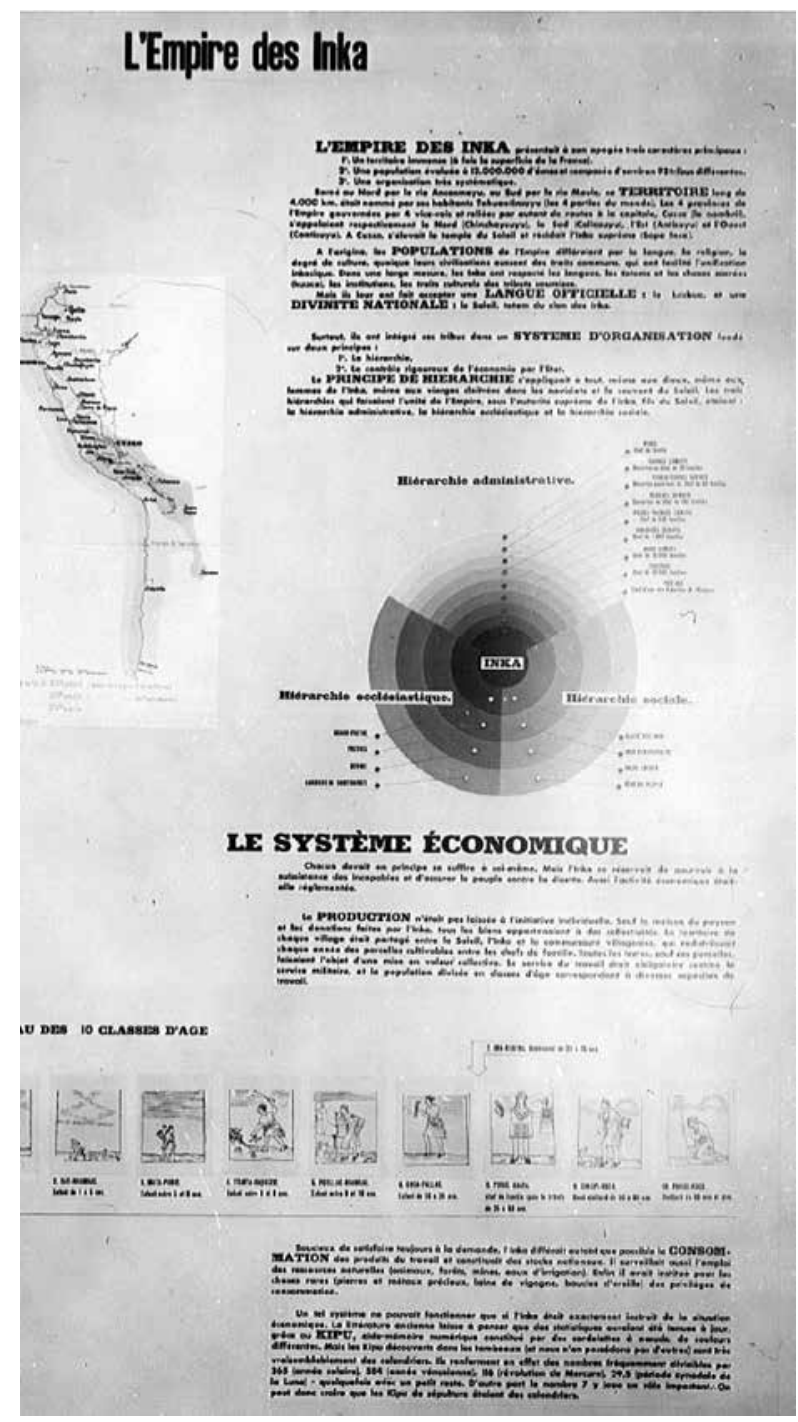

Fuente: archivo del ICANH.

La Resistencia desde 1940, hasta que dos de sus gestores, Anatole Lewistky y Boris Vildé fueron detenidos y posteriormente ejecutados en $1942 .{ }^{\circ}$ De manera paralela, el discurso sobre las razas elaborado por el

8 Además las mujeres judías que trabajaban en el museo fueron detenidas y enviadas a campos. museo y el instituto fue aprovechado por quienes apoyaban al Gobierno de Vichy y la ocupación alemana y transformado en propaganda antisemita hasta el punto de que una nueva plaza sobre judaísmo fue creada en la Soborna por orden del Ministerio de Educación y Georges Montandon, quien luchó por dirigir el museo y reordenar los 
estudios de etnología en un sentido racista e imperialista, organizó una exposición itinerante con el título Los judíos y Francia cuyo propósito central consistía en que la población francesa fuese capaz de reconocer visualmente judíos en las calles y de informarse de la nueva legislación antisemita (Conklin, 2013).

Toda esta situación se reflejará en la primera entrega de la Revista del Instituto Etnológico Nacional de Colombia, en la que Paul Rivet abre la publicación con su emblemático texto "La etnología, ciencia del hombre". En esta especie de manifiesto, el etnólogo francés advierte sobre la equivocación absurda de hablar de una raza pura y afirma que la preocupación y el complejo de inferioridad de ciertos espíritus por la diversidad étnica de América no tienen objeto: "Todo hombre debe comprender y saber que, bajo todas las latitudes, bajo todas las longitudes, otros seres, sus hermanos, cualquiera que sea el color de su piel o la forma de sus cabellos, han contribuido a hacer su vida más dulce o más fácil” (Rivet, 1942, p. 5). Entre líneas se puede adivinar que cuando Rivet afirma que la ciencia del hombre es una "escuela de optimismo" que enseña "la fraternidad, la justicia y la solidaridad", y que el laboratorio del etnólogo "debe ser una casa de vidrio" donde "su mirada pueda contemplar todo el prodigioso esfuerzo de la investigación humana", estaba ciertamente evocando de manera indirecta su museo (Rivet, 1942, pp. 1-5).

Si bien para Hernández de Alba el Museo del Hombre representó "el más técnico de los museos" (Hernández, citado en Barragán, 2014, p. 33) y la influencia de Rivet y Mauss como pensadores y gestores de instituciones culturales fueron determinantes en su vida profesional, los investigadores han ignorado hasta el momento la fuerte impresión que causaron en él los museos norteamericanos que tuvo la oportunidad de visitar inicialmente en su paso por Nueva York, regresando de Francia en 1941 (Barragán 2014, p. 134) y por una temporada más extendida en 1944, con el apoyo del "Smithsonian Institution por medio de la Gugenheim Foundation" (Perry, 2006, p. 46). Como se puede ver en los textos sobre museología escritos por Luis Alfonso Sánchez y Blanca Ochoa en 1945, que serán analizados más adelante, a pesar de que para 1944 Hernández de Alba ya se había retirado del Instituto Etnológico, su influencia aún era palpable en sus colegas. En su archivo existe un documento sin fecha precisa con el título de "A través de un Museo en Norteamérica" (1948?), que por el tono y las referencias podemos adivinar que fue una conferencia sobre el Museo de Brooklyn impartida luego del regreso de su segundo viaje a Norteamérica. Para no interpretar este hecho de manera individual y aislada es necesario advertir que el apoyo al arqueólogo y etnólogo colombiano estuvo enmarcado dentro de una política cultural de buena vecindad que el Gobierno de Estados Unidos promovió durante la segunda guerra mundial para fortalecer las relaciones con el resto del continente americano. Así, la circulación de intelectuales latinoamericanos en institutos estadounidenses estuvo acompañada de giras y estadías de investigadores norteamericanos en Latinoamérica y de exhibiciones itinerantes de arte latinoamericano en diferentes museos de Norteamérica (Sadlier, 2013).

Lo primero que vale la pena advertir es que los mismos aspectos que habían resultado valiosos para Hernández de Alba en 
Imagen 2. Modelos arquitectónicos de América Central construidos por Herbert Spinden en el Museo de Brooklyn, 1937 1 fotografía, sepia, $20,6 \times 25,5 \mathrm{~cm}$

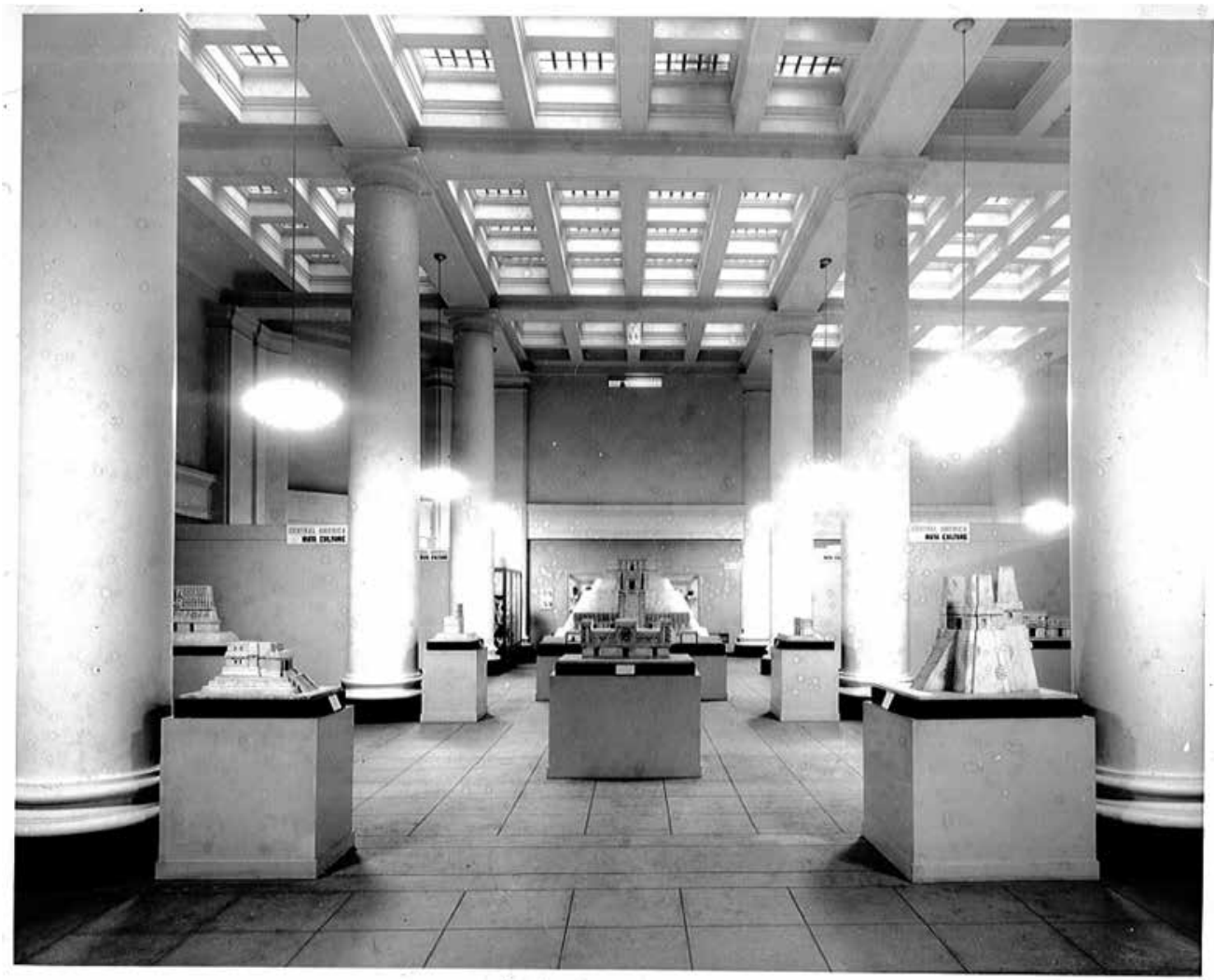

Fuente: archivo del ICANH.

el Museo del Hombre fueron apreciados en el caso de Brooklyn, aunque aquí se le presentaron desde una perspectiva distinta. En ambos casos, por ejemplo, existía un proyecto educativo, pero mientras el énfasis en París se dirigió cada vez más a las masas obreras, en el caso de Brooklyn una parte importante de esta función iba dirigida a los niños, aspecto que había sido central para el Museo Arqueológico Nacional, que desde sus inicios involucró de manera activa a los estudiantes de las escuelas de Bogotá. ${ }^{9}$ Sin

9 En el segundo Boletín del Museo Arqueológico de Bogotá se ofrece la siguiente estadística de visitas: "Entre el 1 de julio de 1942 y al 15 de julio de 1943: Estudiantes no en comunidad 4000. Estudiantes duda, la función pedagógica estaba igualmente ligada en Brooklyn, como en el Museo del Hombre, a su función política. Sin embargo, aquí también existía una diferencia significativa, pues lo que se pretendía en ese caso era americanizar la población migrante que creció en ese distrito de manera exponencial durante los años treinta (Rossof, 2005, p. 47).

en comunidad 3237. Particulares 3311. Total 10548" (Hernández de Alba, noviembre de 1943, p. 8). Esto muestra que el mayor porcentaje de visitantes al museo, al menos durante el año cuando se ofreció el dato, fueron niños y jóvenes. Asimismo, no sobra agregar que esta inquietud ya estaba despierta en el arqueólogo y etnólogo colombiano, quien en 1937 había publicado unos cuentos infantiles sobre la Conquista. 
Para formar una completa nacionalidad en el espíritu del niño, el Museo comienza por poner a su alcance y hacerle admirar todas las cosas de las culturas indígenas (39) siendo otros niños quienes explican cómo vive el indio americano (40) y teniendo todos el derecho de examinar pieza por pieza el vestido del niño indígena. (Hernández de Alba 1948?, p. 2)

De hecho, mecanismos como el diorama, que en los últimos años ha sido objeto de fuertes críticas en el campo de la historia de la museología, aparecieron ante la mirada de Hernández de Alba como medios eficaces para el educación:10 "Pues Señor, aquí tenemos un diorama de la vida en Egipto, mil veces más claro que un capítulo de la historia del Padre Ruiz Amado en que tuve la desgracia de no poder estudiar. La cuna de la imprenta (31) con el buen viejo Guttemberg, aquí está" (Hernández de Alba, 1948?, p. 6).

Otro aspecto que llamó la atención del arqueólogo y etnólogo colombiano tiene que ver con la importancia que esta institución le otorgó al arte indígena americano. Esto se debe, por un lado, a la colección que Stewart Culin, el curador del Departamento de Etnología (1903-1929), había formado a partir de sus viajes por Estados Unidos (Fane et al., 1992, p. 23), pero sobre todo al trabajo de Herber Spinden, quien entre 1929 y 1950 fue curador del mismo departamento, renombrado por él como Departament of American Indian Art and Primitive Cultures, a

10 "Los dioramas son máquinas significantes. Las máquinas son intervalos de tiempo en los organismos sociales que las crearon. Las máquinas son mapas de poder, momentos detenidos de las relaciones sociales que, a su vez, amenazan con gobernar a los vivos". (Haraway, 2015, p. 134) partir 1936 y hasta 1947 (Brooklyn Museum, 2001, p. 4). Spinden, a quien Hernández de Alba se refiere en su conferencia, fue un experto en el estudio del arte maya, y realizó varios viajes por Suramérica impartiendo conferencias y recolectando objetos (Rosoff, 2005, p. 50). Como curador fue un defensor de derribar las fronteras de jerarquización y definición de los objetos artísticos. Su afirmación de que "existe belleza en algodón tanto como en seda, en cobre tanto como en oro" (Spiden, 1919, citado en Rosoff, 2005, p. 50) y su forma de readecuar y exhibir las colecciones de objetos americanos resultan elocuentes. Tal como lo relata Hernández de Alba, el salón de México reunía "lo antiguo y lo moderno (4), bajo relieve maya, cerámica y vidriería moderna, columnas de iglesia misional y un santo pintado en piel de búfalo". Y el "gran salón de artes primitivas (5) con su alta columnata y su luz cenital" parecía alargar "las maquetas de edificaciones mayas de centro-américa" (Hernández de Alba 1948?, p. 5), que por cierto habían sido encargadas por el mismo Spiden como parte de un ambicioso proyecto (Rosoff, 2005, p. 50).

Además de la atención a la curaduría del arte indígena americano y a la labor educativa del museo, Hernández de Alba mostró interés en la distribución de sus "servicios internos y técnicos". La biblioteca, para el gran público y los especialistas, los talleres de los obreros carpinteros que diseñaban los dispositivos de exhibición en el sótano, el laboratorio de restauración, cuyos investigadores trabajaban de la mano con los paleógrafos y dibujantes de la editorial, y algo de especial importancia, el estudio de fotografía. Este aspecto resulta clave, ya que gracias a esta sección el museo podía hacer un 
trabajo de divulgación activo de sus colecciones y servicios. Ya en 1928 Henri Rivière, el colaborador de Rivet, se había servido de esta ayuda para dar una conferencia y para preparar el Museo del Hombre, recibiendo una colección de 78 fotografías de los mejores museos norteamericanos (Conklin, 2013, p. 107). Algo similar comenta Hernández de Alba, que afirma sobre el fotógrafo: “Este buen mozo trabaja como pocos en la ampliadora que va a permitir estudiar detalles imperceptibles de un objeto, vender copias de obras maestras y que me permitió hacer esta charla iluminada" (Hernández de Alba 1948?, 5). En síntesis, a diferencia de la crisis que había tenido lugar en el museo de Rivet antes y durante la ocupación nazi, la institución norteamericana parecía aumentar su capacidad y autonomía durante la guerra. Esto narra Hernández de Alba en su texto:

Haciendo totalmente la guerra total, al tiempo que en los parques se levantan edificaciones temporales para alojar soldados hombres o mujeres, en el mismo momento en el que el Pentágono, por ejemplo, ese gran edificio del Ministerio de la Guerra, ocupa treinta mil empleados; en ese mismo instante las instituciones culturales siguen su vida activa, el investigador no levanta su vista del objeto de sus búsquedas, la cátedra permanece ocupada y el arte continua expresándose. Y más aún: el ritmo del estudio se ha apresurado como si hubiera, a más de la urgencia de soluciones prontas, la idea serena de que mañana bien pueden los brazos estar quietos y la idea abandonar los cerebros. (Hernández de Alba, 1948?, p. 2)

Hacia el final de su conferencia, Hernández de Alba cuenta una anécdota sobre una niña colombiana que regresaba con él al país luego de recibir tratamiento médico financiado por un filántropo norteamericano; ante la pregunta de los reporteros sobre su regreso a Colombia, la niña contestó con la frase “Oh, no more Charalá [...]", con lo cual dio pie al arqueólogo y etnólogo de reclamar al Ministerio de Educación y la Dirección de Extensión Cultural más recursos para que "al presentar las culturas de los abuelos indios" pudieran "las juventudes nacionales 'sentir las emociones de antiguos triunfos que ganó el hombre hacedor, el hombre soñador, el hombre inextinguible artista'" (Hernández de Alba 1948?, p. 6). Desafortunadamente, lo que se puede rastrear en la historia de los impresos del museo arqueológico presenta un panorama distinto al que se deseaba.

\section{LOS PRIMEROS AÑOS (1938-1953): LA HISTORIA A PARTIR DE LOS IMPRESOS Y LOS DEBATES SOBRE MUSEOLOGÍA}

La historia de estos museos se puede adivinar a través de un repaso a sus impresos elocuentes, pues a pesar de que varios investigadores participaron activamente en la creación y desarrollo de ambas instituciones, ${ }^{11}$ los rumbos que tomó cada una produjeron resultados distintos. El Boletín del $\mathrm{Mu}$ seo Arqueológico publicó su primer número en febrero de 1943; se esperaba que fuera el órgano principal de difusión del museo con una publicación bimestral que diera cuenta de los avances de la etnología, de estudios sobre "culturas prehistóricas de Colombia", de los nuevos objetos que llegaban al museo

11 Gregorio Hernández de Alba, Luis Alberto Sánchez, Luis Duque Gómez, entre otros. 
y de bibliografía colombiana reciente sobre "las materias que nos ocupan" (Hernández de Alba, 1943, p. 1). Sin embargo, dicha publicación tan solo vio la luz en tres oportunidades, quizás por la falta de recursos a la que se refieren sus gestores y promotores, en distintos apartes de los boletines: la publicación del segundo número fue en noviembre de 1943, ocho meses después de la primera, y la tercera en junio de 1944. Un poco menos desafortunada fue la historia del Boletín de Arqueología, que tuvo 17 números, publicados entre 1945 y 1951, siendo sus primeros dos años los más activos, tanto por la cantidad y regularidad de la publicación de sus números, como por la participación en ellos de varios investigadores con distintos enfoques: textos sobre arqueología, etnología, antropología, lingüística, indigenismo, museología, historia y geografía, conforman el rico contenido del boletín en 1945 y 1946.

En contraste con estos primeros años, los números del 1 al 6 publicados en 1951 fueron en su totalidad las investigaciones arqueológicas en el departamento del Magdalena de Gerardo y Alicia Reichel-Dolmatoff realizadas entre 1946 y 1950 (Reichel-Dolmatoff y Dussan, 1951). Con esta reducción de autores y enfoques se diluyó ese espíritu colectivo de participación y debate, presente en los primeros años del Boletín. No sobra agregar que la Revista del Instituto Etnológico tuvo una historia similar, aunque con el agravante de que su último número es un trabajo sobre los Arhuacos realizado por el Padre José de Vinalesa (1952), acompañado de la autorización de las respectivas censuras (eclesiástica y de la orden) y escrito con un lenguaje alambicado y una retórica que hace evidente la carga ideológica de carácter religioso de esta investigación. Algo similar a lo que se rastrea en las publicaciones sucedió con el proyecto del Museo Arqueológico, que a pesar de no contar con muchos recursos, luchó a toda costa por mejorar sus condiciones y ofrecer actividades de calidad para sus usuarios (particularmente para investigadores, maestros de escuelas y estudiantes); no obstante, las condiciones para su fortalecimiento no se dieron. El museo pasó de estar ubicado en unas salas de la Biblioteca Nacional a ocupar un espacio del antiguo Panóptico, y en 1948 quedó absorbido y anexado como sección del renovado Museo Nacional, que con sus "tres grandes categorías (arqueológicas y etnográficas, históricas y de bellas artes)" terminó de ocupar el resto del edificio. "A partir de este año, y hasta 1960, no hay un solo registro de entrada de piezas en los libros de registro de las colecciones" (Botero, 2001, p. 57).

A diferencia de esta historia, la de los impresos sobre el Museo del Oro revela otra realidad. Tal como se comentó más arriba, la primera vez que aparecieron algunas de sus piezas exhibidas fue entre marzo y septiembre de 1942 (No. 172 a 179), en la Revista del Banco de la República, publicación enteramente dedicada a temas económicos. Así, las fotografías impresas en un papel especial que ocupan páginas enteras y aparecen acompañadas de breves leyendas cumplen la función de ornamentos de la revista. El texto general que acompaña estas reproducciones se refiere a "la colección de orfebrería indígena del Banco de la República" (1942, p. 145). Solo en 1943 y con motivo de la celebración de los 20 años de historia del Banco, apareció en la misma revista la denominación de esta colección como Museo del Oro, aunque aún no fuese accesible para el público, por encontrarse expuesta en la sala 
de juntas del Banco, y por estar restringido su acceso solo a personalidades representativas, y sobre todo a extranjeros (Sánchez, 2003, p. 14). El primer catálogo dedicado enteramente a las piezas fue publicado en 1944 con el título de El Museo del Oro. Tal como lo escribe Luis Alfonso Sánchez en el boletín de febrero de 1945, se trató de uno "de los mejores alardes editoriales hechos en Bogotá", con 48 planchas a color, acompañadas de dos mapas y tres textos introductorios (Sánchez, 1945, p. 89). En 1948, se publicó un nuevo catálogo con el mismo esquema, aunque esta vez se agregó una pintura titulada La leyenda del Dorado, un mapa arqueológico de carácter artístico de autoría de Luis Alberto Acuña y otros breves textos. En 1950 se publicó El estudio inicial de las colecciones del Museo del Oro escrito por el antropólogo mexicano Carlos R. Margain, y en 195380 masterpieces from the Gold Museum, catálogo acompañado de un texto escrito por el arqueólogo español José Pérez de Barradas, con motivo de una exposición de parte de la colección en el Metropolitan Museum of Art de Nueva York. Ambas publicaciones sirvieron como base para el posterior trabajo que Pérez de Barradas realizó a partir de 1954 y que se publicó en cinco volúmenes de gran formato con el título de Orfebrería Prehispánica de Colombia. El conjunto total de publicaciones en las que se evidencia una inversión significativa de recursos económicos es el correlato de la historia inicial de esta colección, que a pesar de no estar disponible para los bogotanos pudo viajar a otros museos del mundo rotulando algunas de sus piezas como masterpiecies. Mientras el Museo Arqueológico luchaba por un proyecto que no fue posible: construir un edificio para albergar su sede al lado de la Biblioteca Nacional, con toda infraestructura para convertirlo en un laboratorio de pensamiento e imaginación (Botero, 2009, p. 204), la colección de orfebrería pasó de la sala de juntas del Banco a ocupar un salón exclusivo en la nueva sede de la entidad en 1959 y posteriormente, en 1968, conquistó un espacio en el corazón de la ciudad, con un edificio construido especialmente para que cumpliera, ahora sí, las funciones de un museo (Sánchez, 2003, p. 23).

Si la historia de estos museos que se puede adivinar a través de un breve repaso a sus impresos muestra tales recorridos en direcciones opuestas, indagar en las formas de concebir la museología y los objetos en estas dos instituciones quizás sirva para explicar los debates implícitos que se desarrollaron en torno a las funciones que debía cumplir un museo de arqueología. Desde que se publicó el primer Boletín del Museo Arqueológico (1943), el texto inaugural escrito por Gregorio Hernández de Alba ataca una visión del museo como lugar para contemplar las piezas como un "fenómeno de mera estética"; el objeto arqueológico no es "una cosa que al mirar en una vitrina nos parece más o menos bella. ¡No! Esa tal cosa [...] es un verdadero documento que al estudiarse ha de decirnos, a los hombres de hoy, lo que su artífice u obrero sintió, creía y conocía" (Hernández de Alba, 1943, p. 1). Por ello, era fundamental que las exposiciones estuviesen acompañadas de intermediarios, que a través de la palabra y de todo un trabajo de difusión hicieran que cada cosa pudiera "presentarnos viva y en función esa época desconocida por lejana y esos hombres incognitos de que nos vino hasta llegar a un estante del Museo" (Hernández de Alba, 1943 , p. 1). Es irónico, aunque comprensible, que el mismo Hernández de Alba, 
encargado de escribir el texto introductorio del primer catálogo del Museo del Oro (1944) afirme en un tono sutilmente burlesco que la orfebrería indígena

[...] llegó a presentar ejemplares tan hermosos como los que se ven en las fotografías y que una dama elegante hoy no vacilaría en llevar como adornos lucientes y no desdeñaría ciertamente el arreglar sus cejas con una de esas admirables pinzas depiladoras que nuestros abuelos de estas tierras de América usaron para arrancar sus pelos, buscando un ideal de estética del cuerpo. (Hernández de Alba, 1944, p. 9)

Dos textos sobre museología que fueron publicados en los boletines de arqueología de febrero y agosto de 1945 permiten ahondar un poco más en este problema. El primero se titula Organización de Museos y fue escrito por Blanca Ochoa Sierra, encargada, junto con Edith Jiménez, de la sección de museología del Museo Arqueológico. El segundo, titulado Museología, fue escrito por Luis Alberto Sánchez, quien aunque también estaba vinculado al Museo Arqueológico, dedicó la mayor parte de su tiempo a la organización, exhibición y catalogación de las piezas del Museo del Oro, así como a la negociación de algunas de sus colecciones (Sánchez, 1945, p. 89). Para Blanca Ochoa (1945), no había "nada más inútil ni más muerto, que un museo" destinado "a atraer la curiosidad del público o a satisfacer los caprichos y gustos de determinados grupos sociales", concepción que ella consideraba "deplorablemente" la más generalizada. En su lugar el museo debía concebirse como un "organismo vivo" que sirviera como centro de "investigación, enseñanza, divulgación y conservación" (pp. 45-46). Para Ochoa, esto implicaba que el valor de cada objeto solo se daba por su contexto de hallazgo o por la relación que se pudiera establecer entre él y el resto de la colección; lo obtenido en excavaciones podía ofrecer datos sobre aquello que se habían adquirido en colecciones particulares y las piezas exhibidas podían servir para adelantar trabajos de comparación con nuevos hallazgos.

Esta concepción también implicaba emplear todos los medios posibles para la reproducción de objetos y para su máxima capacidad de visualización, tal como Paul Rivet se refería metafóricamente al laboratorio del etnólogo - según lo hemos citado más arriba-, no como una torre de marfil, sino como una casa de vidrio (Rivet, 1942, p. 1). De acuerdo con ello, se realizaron fotografías, dibujos, moldes de yeso y copias de varias piezas que circularon en la ciudad y en museos regionales (Duque, 1946, p. 262); asimismo, este trabajo debía estar apoyado por la elaboración de "maquetas, esquemas, explicaciones sintéticas, mapas, etc." que acompañaran la presentación de los objetos. Todo ello apuntaba a que el conjunto general de la colección arrojara pistas sobre las sociedades desaparecidas. El contacto total de estos objetos con el entorno, así como su relación estrecha con vestigios humanos, es decir, su presencia absolutamente cercana de la tierra y la muerte, era justamente lo que los dotaba de vida y valor. Esta relación era la que debía reproducirse en el museo a través de diferentes medios. Así, los retos más urgentes de la institución consistían en la articulación de sus diferentes funciones: que la excavación no estuviese separada de la conservación, y que la investigación pudiera traducirse en enseñanza. 
Más que un discurso de Ochoa, esta concepción se rastrea en todos los informes publicados en las revistas del Servicio de Arqueología y del Instituto Etnológico. De igual manera, los museos regionales, como el arqueológico de la Universidad del Cauca en Popayán o el Museo de Sogamoso, compartían esta política. Henri Lehmann, quien había trabajado en París con Rivet $\mathrm{y}$ fue el cofundador y director del museo arqueológico en Popayán, afirmaba que la mayoría de los objetos "provenían de exploraciones y excavaciones" o a lo sumo que habían sido compradas "al pie de la guaca" (1945, p. 329). También consideraba que parte de la colección estaba destinada para el estudio, ya que el carácter repetitivo hacía que no fuera necesario exhibirlas al público general. Tanto en éste como en los otros museos arqueológicos oficiales en Colombia, no se puede ignorar la influencia internacional que había llegado a través de Hernández de Alba, Paul Rivet y otros intelectuales como Lehmann. Para el caso preciso de Blanca Ochoa y Edith Jiménez, es necesario mencionar a los arqueólogos peruanos Julio César Tello y Rebeca Camellón, pues como lo cuenta Marcela Echeverri, luego de graduarse de la Normal, Ochoa y Jiménez hicieron su especialización en Arqueología en Lima y contaron con su apoyo (Echeverri, 2007, p. 78). La figura de Tello, como arqueólogo indígena, fue fundamental en la historia de esta disciplina en el Perú, y al revisar textos como "El Museo de Arqueología Peruana" escrito en 1924 con motivo de su inauguración, se encuentran varias coincidencias con respecto a lo que planteaba Ochoa en su texto: primero, una crítica enérgica a la consideración de estas instituciones como meros espacios de distracción para el pueblo y los turistas; segundo, su defensa como custodio de las reliquias, centro de investigaciones científicas y centro educacional, todo ello claro está en función de una futura "prosperidad étnica" capaz de "reconsagrar definitivamente la nacionalidad" (Tello, 1967, pp. 105-110).

La visión del museo como un conjunto de prácticas de conocimiento fue llevada más lejos por Gregorio Hernández de Alba tras su partida a Popayán en 1946, a trabajar al Instituto Etnológico del Valle del Cauca. Al ver que los caminos se cerraban en Bogotá, debido a un problema con Paul Rivet al que se han referido varios investigadores, Hernández de Alba renunció a su trabajo en la capital. Esta situación, muy probablemente acompañada de una conciencia cada vez más lúcida sobre la escasez de los recursos económicos para crear instituciones culturales como las que había tenido la oportunidad de conocer, lo llevó a concebir proyectos como el de Haga un museo en su escuela, mediante el cual pretendía que con los medios más rudimentarios cada maestro promoviera la formación de colecciones entre sus estudiantes, y con ello superara la idea de que solo en las letras "se esconden los conocimientos y se refugia la enseñanza". "Si recoger y presentar en buenas condiciones las cosas dichas, será un auxiliar educativo, otra ventaja que ello trae consigo es hacer apreciar y conocer mejor NUESTRAS COSAS, las obras de las gentes que nos precedieron..." (Hernández de Alba, s. f.). Eso sí, cada cosa debía venir acompañada de su propia historia, para que la enseñanza fuera completa y verídica.

En contraste con estas ideas, el artículo de Luis Alfonso Sánchez (1945) presenta otro panorama, pues la concepción de museología que expone se vincula desde el 
comienzo al espacio construido: “Así como en la arquitectura contemporánea la edificación no puede considerarse como un simple rectángulo rodeado de fachadas [...], tampoco debe considerarse la constitución del salón de museo o del Museo en general, como una simple caja" (p. 339). Para Sánchez (1945), más que un etnólogo o un arqueólogo, el museólogo debía ser "un artista decorador profesional", es decir, un "perito en el conocimiento del color, de la luz y de la forma", pues los principales problemas del museo eran "problemas de espacio" y de exhibición: "el reflejo, la contraluz, los fondos de color inadecuado, los ruidos, la desproporción de las vitrinas" (1945, pp. 339-340), etc. Con lo afirmado hasta aquí, se puede pensar que el texto de Sánchez trataba desde una perspectiva distinta el problema a como lo proponía Ochoa, y no necesariamente opuesta. Sin embargo, es necesario subrayar que desde su concepción lo más importante era el valor estético de las piezas y del lugar de exhibición, y no su valor documental y pedagógico. De hecho, en su planteamiento de un museo ideal consideraba necesario que todos los espacios estuvieran aislados unos de otros (investigación, exhibición, administración), que las salas más grandes fueran ocupadas por objetos "de excepcional importancia" por su monumentalidad y belleza, y que los de interés "simplemente" documental pudieran pasar a salas pequeñas. Es decir, lo que para Ochoa era la función central, aquí se convertía en una función secundaria.

Esta concepción del museo también creaba unas formas de exhibición y valoración opuestas de las piezas arqueológicas. Para Sánchez (1945), solo los museos de ciencias naturales debían "restituir el objeto de exhibición a lo que se podría llamar su propio ambiente", mientras que en los museos de arte, "el objeto debía ser sustraído a cualquier influencia que le impidiera mostrarse por sí solo" y de manera "airosa" (p. 340). Si bien en este punto reconoce que los museos arqueológicos son un caso distinto por el desconocimiento general del público de los objetos exhibidos, concluye que la solución radica en la disposición de las piezas, y de esta manera se aleja de la concepción de Hernández de Alba y Blanca Ochoa, que ligaban la efectividad de la exhibición a la palabra hablada y a la historia de los objetos. Sin duda, este texto puede considerarse el modelo que siguió el Museo del Oro, pues cuando presentó sus piezas en las publicaciones impresas y en las vitrinas, la cláusula de la sustracción del objeto de cualquier influencia, como medio de exaltación de su valor, ya no documental sino estético, se cumplió en ambos soportes de exhibición. En segundo lugar, al darle el principal énfasis a lo suntuario del material y a las técnicas de orfebrería - los "pulimientos de gran belleza y delicada ejecución de los más complicados adornos" (Hernández de Alba, 1944, p. 4) -, se le dio entrada a estos objetos al ámbito de las "obras maestras" de arte. Así, el valor documental que defendía el Museo Arqueológico, basado en la premisa de la conexión del objeto con otros objetos y con su entorno y su historia, aquí se invertía, para abrirle paso a una valoración que se cumplía mediante su aislamiento. Es curioso que al pensar ya no en los objetos individuales, sino en las colecciones, se trastocara por completo esta forma de valoración. Por un lado, el crecimiento de la colección del Museo del Oro se percibía como un logro ("más de 5000 piezas posee ya el Banco de la República" afirma Hernández 


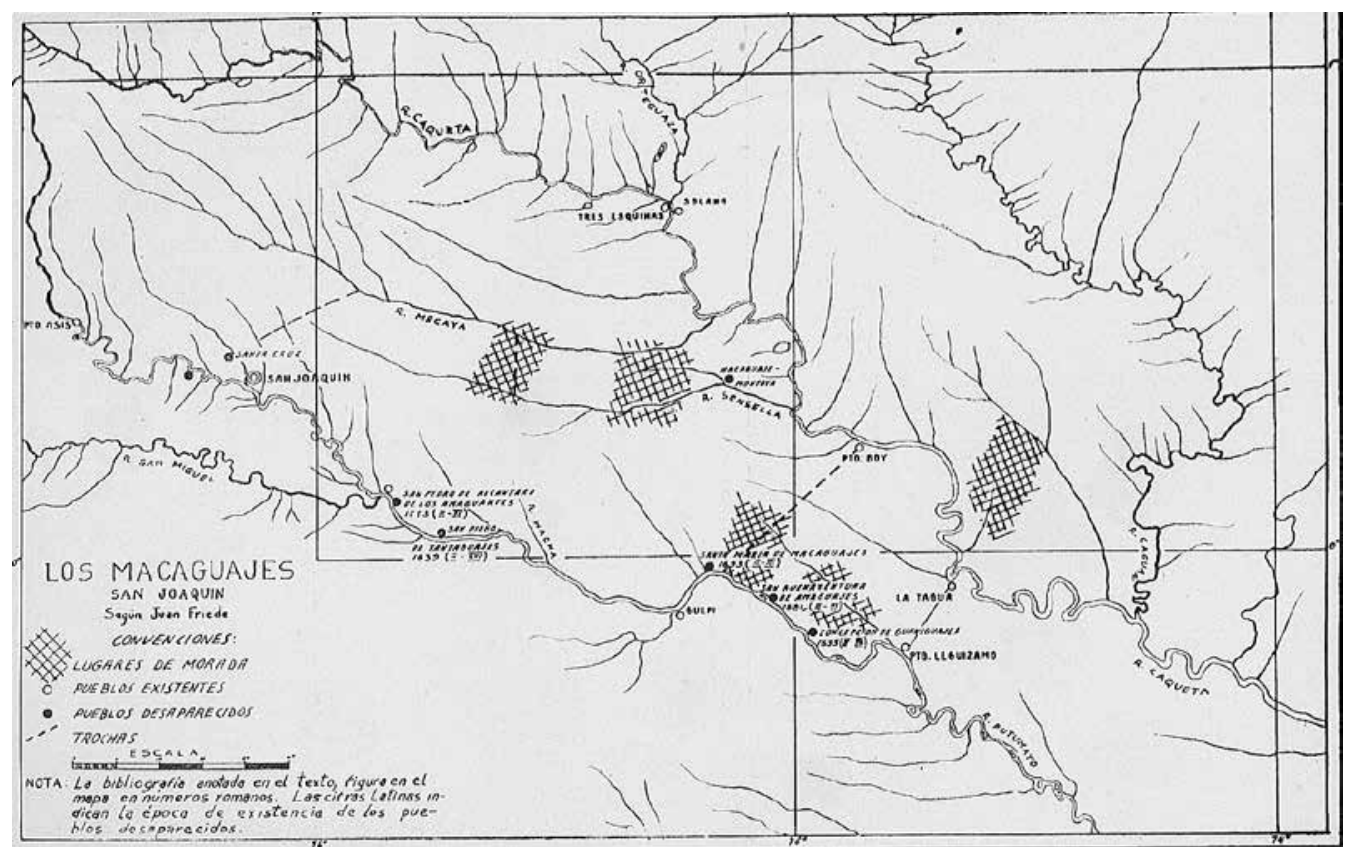

Fuente: Friede (1945).

de Alba (1945, p. 5) en el catálogo de 1944), mientras que para el Museo Arqueológico el aumento de su colección representaba un peligro por el "hacinamiento de piezas" que amenazaba con desbordar y desintegrar la institución, de por sí desprovista de un buen local para albergarlas (Sánchez, 1945, p. 342).

Finalmente, no obstante las divergencias en la concepción de la museología, ambos museos decidieron darle sentido a sus colecciones a partir de su asociación con el espacio geográfico. Sin embargo, este aparente acuerdo no nos debe llevar a engaños. Si bien en ambas instituciones se elaboraron y publicaron mapas arqueológicos, el significado de la geografía en cada una de ellas es distinto. Para el grupo del Museo Arqueológico, ligado como estaba al Servicio de Arqueología y al Instituto Etnológico, esta disciplina era objeto de debate y desacuerdo, de evaluación continua y de dudas. Un ejemplo de ello se puede rastrear entre los miembros del Instituto Indigenista, que se había formado de manera voluntaria y actuaba de la mano del museo, ya que ni siquiera entre ellos había un consenso con respecto a la representación del espacio geográfico actual o histórico; mientras Antonio García defendía la literatura sobre la selva escrita en el siglo $\mathrm{xx}$, considerándola como una escuela de conocimiento que anticipaba el "verdadero y propio camino de América" (García, 1945, p. 67), para Juan Friede se trataba de una nefasta influencia para el país" pues impedía "una clara visión de los problemas" que presentaba (Friede, 1947, p. 384). 
Imagen 4. Lámina 1
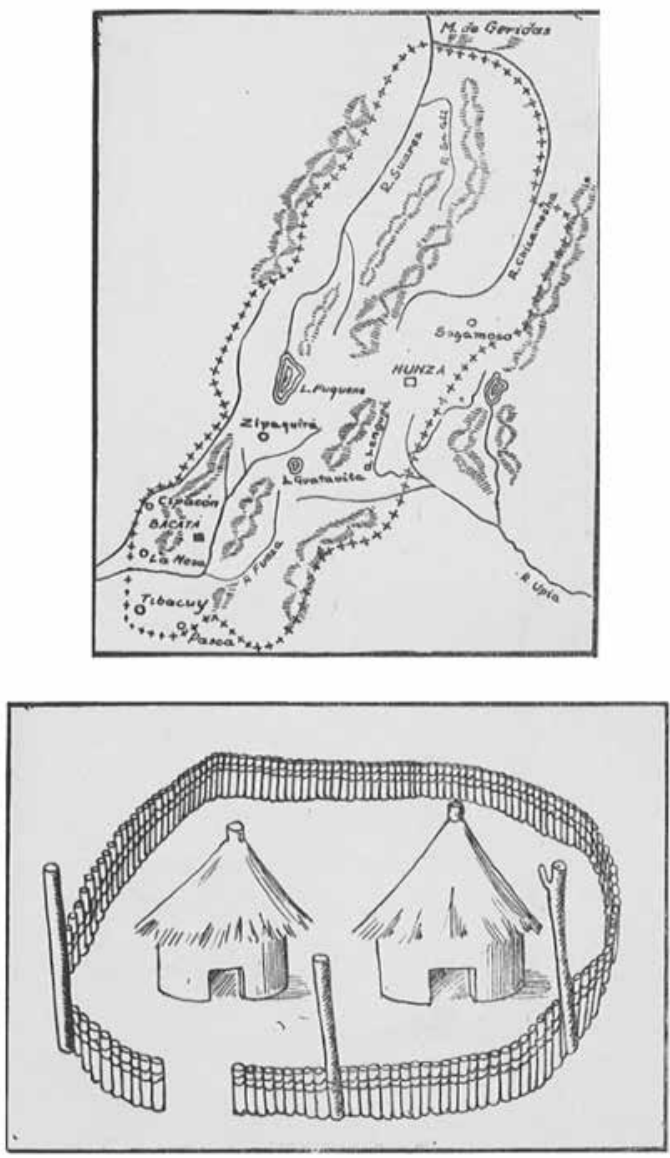

Fuente: Jiménez (1945).

Este solo ejemplo sirve para entender el clima crítico del momento y del contexto. Al revisar el Boletín de Arqueología y la Revista del Instituto Etnológico, nos encontramos con textos dedicados al tema de la toponimia ${ }^{12}$ (que mostraba cómo los variados nombres que ha recibido un territorio lo dotan de una profundidad histórica y lingüística) y con ensayos etnogeográficos, en los que a partir de la experiencia de las expediciones

12 Hay textos de Juan Friede y de Gerardo Reichel-Dolmatoff sobre este tema. se cuestionaba la fidelidad del Mapa de Longitudes y de la cartografía oficial (Guhl, 1945, p. 260). Asimismo, el trabajo en terreno les había enseñado a estos estudiosos y viajeros una lección doble: por una parte, que había existido una enorme cantidad de intercambios y movimientos entre las sociedades prehispánicas, pues se podían hallar objetos en una región que pertenecían a otras bastante alejadas. ${ }^{13}$ Desde otra perspectiva, que el territorio nacional actual no se podía concebir fácilmente como una unidad, por la cantidad de obstáculos de comunicación que separaban algunos espacios de otros. Aquí resulta elocuente citar un fragmento del cuestionario etnográfico que preparó Reichel-Dolmatoff como modelo para quienes emprendieran expediciones: “¿cómo se abre trocha? ¿Rozándola, doblando ramas, quemando? ¿Quién cuida los caminos? ¿Hay una red fija de caminos alrededor de las viviendas? ¿Hay caminos secretos (guerra, caza, abstención entre suegra y yernos, etc.? ¿Cómo se marcan los caminos y las trochas? ¿Doblando ramitas? ¿Poniendo hojas o maderas en cierta forma?" (Reichel-Dolmatoff, s. f.). A pesar de que muy probablemente los mapas que se exhibían en el Museo Arqueológico tenían un carácter didáctico y la función de vincularse con el mapa nacional, como sucede con los que acompañan los textos de divulgación de culturas indígenas de Blanca Ochoa y

13 "Fuera de las numerosas cuentas de collar de formas y tamaños variados, labrados en concha marina, y de los "fotutos" o cornetas, que al decir de Castellanos "se tocaban en los regocijos y en los sangrientos trances de la guerra", y que están indicando de forma inequívoca relaciones culturales de los indios de estas alturas con pueblos de la cosa atlántica, la presencia en Sogamoso de vasijas de barro cocido con técnica y decoración peruanas, abre la consideración, no antes sospechada, de contactos o relaciones culturales con los incaicos, por intermedio de los pueblos del SW de Colombia" (Silva Celis, 1945, p. 104). 
Imagen 5. La metalurgia en América según Rivet

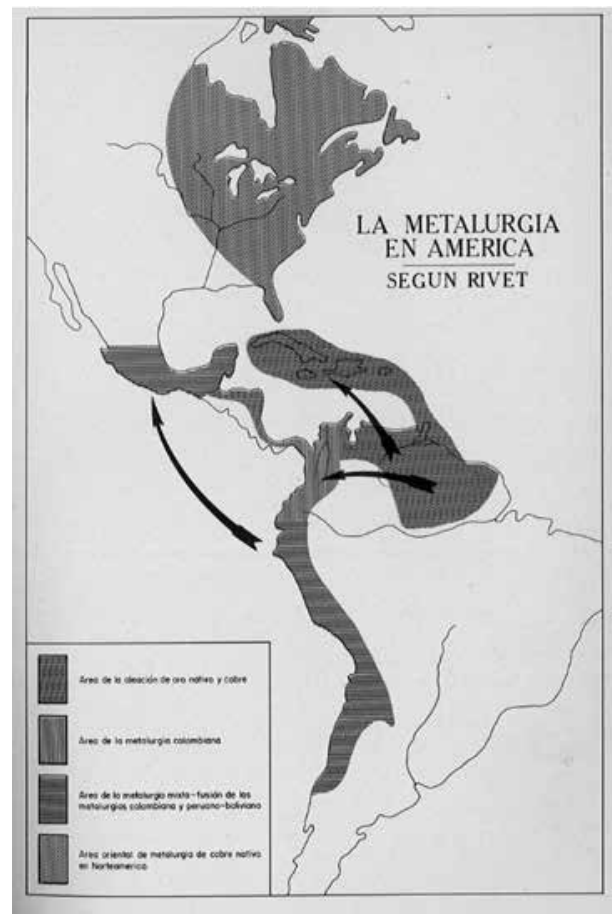

Fuente: Rivet (1945).

Edith Jiménez, los mapas de excavaciones arqueológicas y trabajos etnogeográficos que aparecen en los boletines y las revistas del Servicio de Arqueología y el Instituto Etnológico dan cuenta de una gran diversidad de estilos cartográficos; la mayoría de ellos se ocupan de reconstruir fragmentos específicos del territorio y prácticamente no hay en estas publicaciones mapas completos del territorio nacional. Sin duda todas estas experiencias llevaron a que en las cartas geográficas que fabricaba el museo se subrayara el hecho de que se trataba del "estado actual" de las investigaciones y no de una representación definitiva y cerrada del espacio.

Al contrario de ello, en los primeros dos catálogos del Museo del Oro encontramos repetido un mapa de Paul Rivet sobre la
Imagen 6. Mapa arqueológico de Colombia, Luis Alberto Acuña

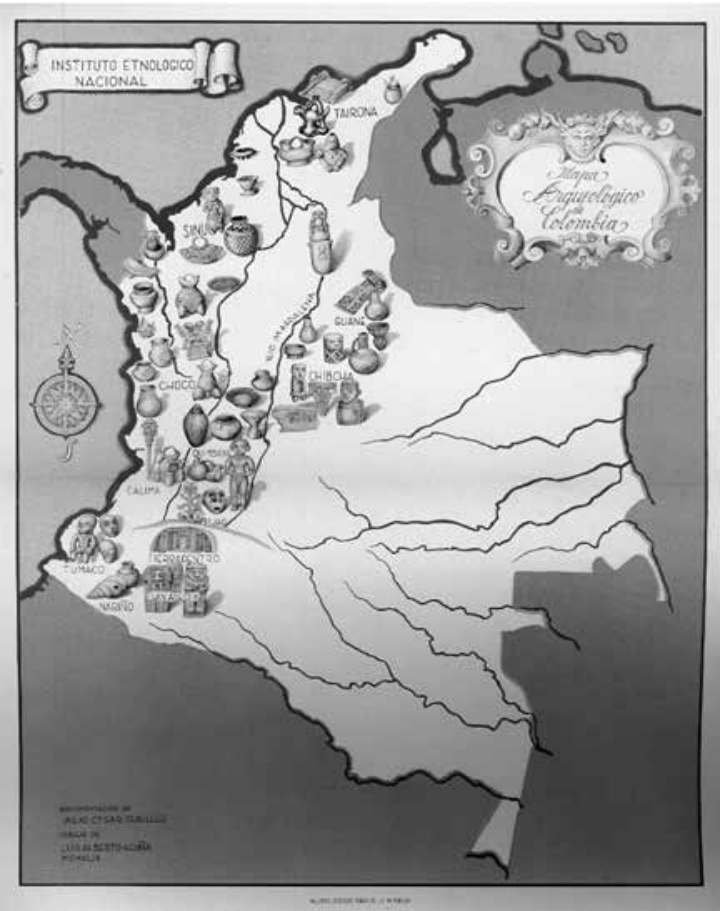

Fuente: Acuña (1945).

metalurgia en América, aunque en su segunda versión aparezca más bellamente elaborado. Asimismo, en la edición de 1948 aparece un mapa artístico elaborado por Luis Alberto Acuña, que refuerza con sus imágenes la asignación de cada cultura a un territorio específico. Sin duda aquí la geografía y cartografía no funcionaban como ciencias problema, sino como medios de ordenamiento y estabilización. Es decir que no se trataba del mapa experimental de los etnólogos, arqueólogos y geógrafos, sino más bien del "mapa-logotipo, al instante reconocido y visible por doquier", del que nos habla Benedict Anderson (1993). ${ }^{14}$

\footnotetext{
14 "El mapa-logotipo, al instante reconocido y visible por doquier, penetró profundamente en la imaginación popular, formando un poderoso emblema de los nacionalismos..." (Anderson, 1993, p. 245).
} 
El punto más álgido de esta estrategia fue llevado a cabo por el antropólogo mexicano Carlos Margain, quien en su estudio de las colecciones creó el término de "estilo-región" (engañoso por su pretensión de claridad y cientificidad) mediante el cual clasificó la colección del Museo del Oro en ocho grupos. En esta operación, sacó de tajo el nombre de Chiriquí para referirse a algunas piezas por considerarlo inadecuado: ¿cuál es la razón de fondo que se intuye para esta decisión?, el hecho de que con ese nombre se denominaba anteriormente una región situada en Panamá; es decir, que todo este asunto de los "estilos-región" debía además de separar pulcramente un conjunto orfebre de otro, recortarse y adaptarse al croquis del mapa nacional. Es irónico que este trabajo se hubiera hecho precisamente a partir de las colecciones del Museo del Oro, donde como dice Margain solo se conocía 1,5 $\%$ de la procedencia de las piezas (Margain, 1950, p. 57).

\section{Conclusión: DOS MANIFESTACIONES DE LA MIRADA ALEGÓRICA}

Para concluir, ¿qué tipo de miradas podemos rastrear en estos procesos de observación, valoración y exhibición del patrimonio arqueológico en Bogotá, durante los primeros años de existencia de ambos museos? Sin duda, en ambos casos se trata de una mirada alegórica, en la que cada "cosa puede significar cualquier otra". ${ }^{15}$ Sin embargo, como lo advierte Michael Taussig en su libro Mi museo de la cocaína (2013), la alegoría cumple con el misterio de la petrificación y

15 Esta es una de las reflexiones de Walter Benjamin sobre la alegoría en El origen del drama barroco alemán (1990, p. 167). la liquidez: es la imagen húmeda de Medusa que al mismo tiempo nos vuelve de piedra (Taussig, 2013, p. 268). Es decir que el proceso de significación de los objetos indígenas podía congelarse y hacerse rígido o abrirse a una cadena infinita de sentidos y relaciones. En nuestro contexto e irónicamente opuesto a lo que solemos pensar, la interpretación de los objetos arqueológicos como obras de arte puso en juego una serie de dispositivos de exhibición que produjeron un efecto de aislamiento para que primara el goce estético sobre la investigación científica o la función didáctica, dando como resultado una especie de petrificación del significado de las piezas orfebres. Este método que se ensayó durante algún tiempo en el Museo del Hombre, donde por indicaciones de Rivière existió un salón de "los tesoros" (Conklin, 2013) y que también fue puesto en juego por Spinden en Brooklyn, se dejó a un lado paulatinamente con el advenimiento de la crisis social y de la guerra (Rosoff, 2005, p. 51) en ambos casos. En su lugar surgió un interés cada vez más comprometido con el análisis social de los objetos en el museo de Rivet, y una visión cada vez más ligada a la educación en el de Brooklyn. Por lo que refieren las fuentes hasta ahora consultadas, en Bogotá las funciones educativas e investigativas tuvieron más peso en el Museo Arqueológico, mientras que en el Museo del Oro primó una visión artística y estética de las piezas que exaltaba su factura, por su refinamiento técnico. A ello se añade el hecho inquietante de que la relación entre los objetos y la geografía fue en el primer caso un asunto diverso y problemático, mientras que en el segundo se cristalizó mediante mapas-logotipo (el mapa artístico de Luis Alberto Acuña), repeticiones (el mapa del origen de la metalurgia según Rivet) y 
formas de ordenamiento del espacio (mediante la noción estilo-región), como la que propuso Margain.

No debemos olvidar que la colección de orfebrería del Banco de la República se inició de manera paralela a una crisis debida a la incertidumbre del valor económico del oro (1942, p. 109). Y tampoco que en el mundo moderno del arte y el coleccionismo, debajo del manto de la "obra maestra", viene siempre agazapado el fetiche de la mercancía. Así que tal vez esa mirada que construyó el Museo del Oro y que aún hoy conserva con algo de corrección y "cirugía estética" no sea otra que la de nuestra enajenación frente al mundo transfigurado en un gran mercado en el que cada cosa nos llama y nos obliga a remitirnos a ella misma, con lo cual se ocultan las relaciones en las que está inmersa. Si con esa pretensión de transformar las piezas de orfebrería en obras de arte se codificaba esa forma de ver, ¿qué tipo de mirada podemos rastrear en el proyecto que anheló el Museo Arqueológico? Quizás mucho menos que una mirada científica; tal vez la aventura de esa generación no sea sino la expresión encubierta de la mirada poética que está implicada en todo acto de volver a nombrar las cosas y de conocer una vez más en ellas la vida sobreviviente.

\section{ReFERENCIAS}

Alonso, G. (Ed.) (2013). Banco de la República: 90 años de la banca central en Colombia. Bogotá: Banco de la República.

Acuña, L. (1945). Mapa arqueológico de Colombia, El Museo del Oro: 1923-1948. Bogotá: Banco de la República.

Anderson, B. (1993). Comunidades imaginadas. Reflexiones sobre el origen y la difusión del nacionalismo. México D.F.: Fondo de Cultura Económica.

Barragán, C. A. (2014). Entre redes científicas, alianzas intelectuales y fricciones políticas: Itinerarios etnológicos de Gregorio Hernández de Alba (1935-1945). En La cultura arqueológica de san Agustín. Gregorio Hernández de alba (1904-1973) (pp. 95-99). Bogotá: Instituto Colombiano de Antropología e Historia [ICANH].

Benjamin, W. (1990). El origen del drama barroco alemán. Madrid: Taurus.

Botero, C. I. (1996). Algunas reflexiones sobre la relación entre museos y patrimonio. Boletín de Arqueología, 11, 57-66.

Botero, C. I. (2001). De la presentación a la representación: el pasado prehispánico en el museo nacional de Colombia. En F. López Barbosa (Ed.), La arqueología, la etnografía, la historia y el arte en el museo (pp. 51-59). Bogotá: Ministerio de Cultura.

Botero, C. I. (2006). El redescubrimiento del pasado prehispánico de Colombia: Viajeros, arqueólogos y coleccionistas 1820-1945. Bogotá: Instituto Colombiano de Antropología e Historia [ICANH], Ediciones Uniandes.

Botero, C. I. (2009). El surgimiento de los museos arqueológicos y etnográficos: Laboratorios de investigación y espacios para la visibilidad, divulgación y exhibición del patrimonio arqueológico y de las sociedades indígenas. En Arqueología y etnología en Colombia. La creación de una tradición científica (pp. 197-219). Bogotá: Ediciones Uniandes.

Botero, C. I. (2010). José de Recasens: la construcción de una tradición científica en Colombia. Antípoda, 285-338.

Brooklyn Museum (2001). Guide to the Records of the Department of the Arts of 
Africa, thePacific Islands, and the Americas (AAPA) 1926-2001. New York: Brooklyn Museum.

Conklin, A. (2013). In the museum of man: race, anthropology, and empire in France, 1850-1950. Ithaca: Cornell University Press.

Duque Gómez, L. (2004) Colombia: Monumentos históricos y arqueológicos. Bogotá: Academia Colombiana de Historia Nacional.

Duque Gómez, L. (1946). Informe del jefe del servicio de arqueología y del instituto etnológico nacional, sobre las labores, desde junio de 1946 a junio de 1947. Boletín de Arqueología, 255-287.

Dussan, A. (1984). Paul Rivet y su época. Correo de los Andes, 70-76.

Echeverri, M. (junio, 1999). El museo arqueológico y etnográfico de Colombia (1939-1948); la puesta en escena de la nacionalidad a través de la construcción del pasado indígena. Revista de Estudios Sociales, (3), 104-109.

Echeverri, M. (2007) Antropólogas pioneras y nacionalismo liberal en Colombia, 1941-1949. Revista Colombiana de Antropología, 43, 61-90.

Fane, D. et al. (1992) Objects of myth and memory. American Indian Art at the Brooklyn Museum. New York: The Brooklyn Museum in association with University of Washington Press.

Friede, J. (1947). ¿Debe y puede Colombia colonizar la selva? Revista de Las Indias, (99), 383-402.

Friede, J. (mayo-junio, 1945). Reseña etnográfica de los macaguajes de San Joaquin sobre el Putumayo Boletín de arqueología (3), 553-567.

García, A. (1945). El indigenismo en Colombia. Génesis y evolución. Boletín De Arqueología, 52-71.
García, N. (2001) Culturas híbridas: estrategias para entrar y salir de la modernidad. Buenos Aires: Paidós.

Gnecco, C. (et. al.) (2010) Pueblos indígenas y arqueología en América Latina. Bogotá: Fundación de Investigaciones Arqueológicas Nacionales, Banco de la República, Ediciones Uniandes.

Goldenweiser, E. A. (20 de marzo de 1940). El actual problema del oro. Revista del Banco de la República, (149), 91-94.

Gruzinski, S. (2004). La ciudad de México: una historia. México D.F.: Fondo de Cultura Económica.

Guhl, E. (1945). El macizo colombiano: informe preliminar de un ensayo etno-geográfico. Boletín de Arqueología, 257-265.

Haraway, D. (2015) El patriarcado del osito Teddy. Taxidermia en el Jardín del Edén. Barcelona: Sans Soleil.

Hernández de Alba, G. (1943). El servicio de arqueología. Boletín del Museo Arqueológico de Colombia, 1-8.

Hernández de Alba, G. (1944). El oro de los indios colombianos. En El museo del oro (p. 9). Bogotá: Banco de la República.

Hernández de Alba, G. (s. f.). Haga un museo en su escuela. Documento del Archivo Gregorio Hernández de Alba, Biblioteca Luis Ángel Arango.

Hernández de Alba, G. (1948?). A través de un museo en Norteamérica. Documento del Archivo Gregorio Hernández de Alba, Biblioteca Luis Ángel Arango.

Jiménez, E. (1945). Los chibcha de Edith Jiménez. Boletín de Arqueología, I(II), 119-133.

Langebaek, C. H. (2009). Los herederos del pasado: Indígenas y pensamiento criollo en Colombia y Venezuela. Bogotá: Ediciones Uniandes. 
Langebaek, C. H. (2010). Diarios de campo extranjeros y diarios de campo nacionales: indiferencias de José Pérez de barradas y de Gregorio Hernández de Alba en Tierradrento y San Agustín. Antípoda, (11) 125-161.

Langebaek, C. H. (2003). Arqueología colombiana: Ciencia, pasado y exclusión. Bogotá: Colciencias.

Lehmann, H. (1945). El museo arqueológico de la Universidad del Cauca en Popayán [Volumen I, Tomo II]. Boletín de Arqueología, (3), 229-255.

Londoño, S. (1989). Museo del oro. 50 años. Bogotá: Banco de la República.

Matos, E. (1998). Las piedras negadas: de la Coatlicue al Templo Mayor. México D.F.: Conaculta.

Margain, C. (1950). El estudio inicial de las colecciones del museo del oro. Bogotá: Banco de la República.

Ochoa Sierra, B. (1945). Museología. Organización de museos. Boletín de Arqueología, 45-48.

Parga, R. (1943). Informe del ministro de educación sobre el servicio arqueológico. Boletín del Museo Arqueológico de Colombia, 2, 2-7.

Paz, O. (2006). Obras completas 7. Los privilegios de la vista II. Arte de México. México, D.F: Fondo de Cultura Económica.

Perry, J. (2006) Caminos de la antropología: Gregorio Hernández de Alba. Bogotá: Ediciones Uniandes.

Perry, J. (2009). La exposición arqueológica y etnográfica de 1938 en Colombia: Un primer intercambio cultural. En C. H. Langebaek y C. I. Botero (Eds.), Arqueología y etnología en Colombia. La creación de una tradición científica (pp. 79-95). Bogotá: Ediciones Uniandes.
Phillmore.J. G. (1942). El valor monetario del oro. Revista del Banco de la República, 173, 109-110.

Pineda Camacho, R. (2014). Hernández de alba: el antropólogo de la república liberal. En C. A. Barragán (Ed.), La cultura arqueológica de san Agustín, Gregorio Hernández de Alba (1904-1973) (pp. 59-95). Bogotá: Instituto Colombiano de Antropología e Historia [ICANH].

Pineda Camacho, R. (2009). Cronistas contemporáneos. Historia de los institutos etnológicos de Colombia (1930-1952). En C. H. Langebaek y C. I. Botero (Ed.), Arqueología y etnología en Colombia. La creación de una tradición científica (pp. 113-171). Bogotá: Ediciones Uniandes.

Reichel-Dolmatoff, G. (s. f.). Cuestionario de etnografía (informe). Bogotá: Instituto Colombiano de Antropología e Historia [ICANH].

Reichel-Dolmatoff, G. y Dussan, A. (1951). Investigaciones en el departamento del magdalena. Boletín de Arqueología, III.

Rivet, P. (1942). La etnología, ciencia del hombre. Revista del Instituto Etnológico, 1-6.

Rivet, P. (1945). La metalurgia en América según Rivet. El Museo del Oro: 1923-1948. Bogotá: Banco de la República.

Revista Bancaria y Aseguradora de Buenos Aires (1942). El problema del oro en los Estados Unidos. Revista del Banco de la República, 178, 314-316.

Rossof, N. (2005). As revealedby art: Herbert Spinde and the Brooklyn Museum. Museum Anthropology, 28(1), 47-56.

S. A. (1941). El patrón de oro. Revista del Banco de la República, (161), 91.

S. A. (1942). La colección de orfebrería indígena. Revista del Banco de la República, (174), 145. 
Sadlier, D. (2013) Good neighbor cultural diplomacy in World War II. Austin: Unniversity of Texas Press.

Sánchez, E. (2003). El museo del oro. Boletín Cultural y Bibliográfico, 40, 3-48.

Sánchez, L. A. (1945). Libros. Boletín De Arqueología, 1, 89.

Sánchez, L. A. (1945). Museología. Boletín de Arqueología, 1, 339-348.

Servicio de Información Panamericana (1940). Excesivas existencias de oro en los Estados Unidos. Revista del Banco de la República, 153, 270-271.

Silva, R. (2005). República liberal, intelectuales y cultura popular. Medellín: La Carreta.

Silva Celis, E. (1945). Investigaciones arqueológicas en Sogamoso. Boletín de Arqueología, 1, 93-112.
Sunkel, G. (Coord.) (2006). El consumo cultural en América Latina. Construcción teórica y líneas de investigación. Bogotá: Convenio Andrés Bello.

Taussig, M. (2013). Mi museo de la cocaína. Cali: Universidad del Valle.

Vázquez de Parga, L. (1954). El museo arqueológico nacional. Noticia de sus colecciones de arqueología española hasta la edad media. IV Congreso Internacional de Ciencias Prehistóricas y Protohistóricas. Madrid, Museo Arqueológico Nacional. Vilanea, J. d. (1952). Indios arhuacos de la Sierra Nevada de Santa Marta. Revista del Instituto Etnológico Nacional. 